\title{
Desiccation, thermal stress and associated mortality in Drosophila fruit flies induced by neuropeptide analogue treatment
}

\author{
Lucy Alford ${ }^{1}$ [ - Richard Marley ${ }^{1} \cdot$ Anthony Dornan $^{1} \cdot$ Julian A. T. Dow $^{1} \cdot$ Ronald J. Nachman $^{2} \cdot$ Shireen A. Davies ${ }^{1}$
}

Received: 15 October 2018 / Revised: 14 February 2019 / Accepted: 21 February 2019 / Published online: 14 March 2019

(c) The Author(s) 2019

\begin{abstract}
Drosophila suzukii is a serious pest of soft fruit worldwide. With the global over-dependence on broad-spectrum pesticides, a strong imperative exists for more environmentally friendly and targeted methods of control. One promising avenue involves employing synthetic neuropeptide analogues as insecticidal agents to reduce pest fitness. Neuropeptides, central to the regulation of physiological and behavioural processes, play a vital role in cold and desiccation survival. Building upon this, the current study investigated the effects of biostable kinin, the cardioacceleratory peptide CAP2b and pyrokinin (PK) analogues (the latter of which have previously displayed cross-talk with the capa receptor), on desiccation, starvation and cold stress tolerance of the pest, D. suzukii, and the closely related non-pest, D. melanogaster. Results demonstrated analogues of the superfamily (CAP2b and PK derived) significantly impacted survival of the target insect under conditions of desiccation stress. However, these peptides enhanced desiccation stress survival in relation to controls, suggesting that they may act as antagonists of the capa signalling pathway in the Malpighian tubules. Of particular note was the ability of analogues 1895 (2Abf-Suc-FGPRLa) and 1902 (2Abf-Suc-FKPRLa) to impact D. suzukii but not D. melanogaster. A focus on native Drosophila CAP2b/PK and kinin sequences in analogue development may yield pure agonists with diuretic action that may reduce desiccation stress survival in the pest flies. In highlighting the PRXamide neuropeptide superfamily more generally, and the structures of promising analogues more specifically, this research will feed the evolution of next-generation analogues and drive forward the development of neuropeptidomimetic-based agents.
\end{abstract}

Keywords CAP2b · Dromekinin · Drosophila suzukii · G-protein-coupled receptors · Insecticide · Peptidomimetics · Pyrokinin

\section{Key message}

- The employment of synthetic neuropeptide analogues represents a novel approach to target-specific and environmentally friendly pest control.

Communicated by A. Biondi.

Lucy Alford and Richard Marley: joint first author.

Lucy Alford

1.alford.02@cantab.net

1 Institute of Molecular, Cell and Systems Biology, College of Medical, Veterinary and Life Sciences, University of Glasgow, Davidson Building, Glasgow G12 8QQ, UK

2 Insect Control and Cotton Disease Research Unit, U.S. Department of Agriculture, Southern Plains Agricultural Research Center, College Station, TX 77318, USA
- Biostable kinin, CAP2b and pyrokinin (PK) analogues were developed and tested ex vivo in Malpighian tubule fluid secretion assays.

- Analogues were subsequently tested in vivo for an ability to reduce the fitness of a pest species (Drosophila suzukii) under a variety of stress conditions relative to a non-pest species (Drosophila melanogaster).

- Results highlight the structure of neuropeptides of the PRXamide superfamily as candidates in the drive for neuropeptidomimetic-based insecticidal agents.

\section{Introduction}

Drosophila suzukii Matsumura (Diptera: Drosophilidae) is a pest of soft fruits worldwide (Asplen et al. 2015) and a close relative of the model organism D. melanogaster. Its pest status is due to the female's use of a specialised serrated 
ovipositor to deposit eggs in ripe pre-harvest soft fruit crops (Atallah et al. 2014; Hamby et al. 2016). Recent research effort has focused on management strategies to minimise further spread of D. suzukii and associated economic losses, with a focus on detection, tracking and trap and bait design (Landolt et al. 2012; Feng et al. 2018; Frewin et al. 2017; Huang et al. 2017), biological control (e.g. Becher et al. 2017; Garriga et al. 2018; Giorgini et al. 2018; Girod et al. 2018; Woltz et al. 2015), harvesting techniques (Leach et al. 2018) and the development of biopesticides (Fanning et al. 2018). However, current management programs still rely heavily on broad-spectrum insecticides (Desneux et al. 2007; Diepenbrock et al. 2017). With the negative effects of chemical insecticides well documented (Pimentel et al. 1992), a strong imperative exists to develop more target-specific and 'greener' methods of pest control.

One promising avenue of pest control research involves the development and employment of neuropeptide synthetic mimetics (Nachman 2009). Neuropeptides are regulatory peptides and, within the insects, have functional roles in growth and development, behaviour and reproduction, metabolism and homeostasis and muscle movement (Altstein and Nässel 2010). Neuropeptides and their receptors (G-protein-coupled receptors, GPCRs) offer promising targets in the development of a new generation of insecticidal agents that selectively reduce the fitness of target pest insects, whilst minimising detrimental environmental impacts (Nachman 2009; Van Hiel et al. 2010; Audsley and Down 2015). Fundamental to this is an enhanced understanding of ligand-GPCR interactions to aid in the design of neuropeptide-based insecticidal agents.

Three neuropeptide families were selected for study including the insect cardioacceleratory peptides (capa, CAP2b; Kean et al. 2002), the pyrokinins (PK; Holman et al. 1986) and the kinins (Holman et al. 1999). Neuropeptides of the capa family were first identified in the moth Manduca sexta (CAP2b; Huesmann et al. 1995). Since their discovery, these neuropeptides have been shown to stimulate heart contractions (Huesmann et al. 1995), rapid fluid secretion by Malpighian (renal) tubules (Davies et al. 1995) and to modulate desiccation and cold tolerance in both Drosophila melanogaster and D. suzukii (Terhzaz et al. 2015). Widely distributed among invertebrates, the capa peptides belong to the PRXamide superfamily that can be further subdivided into three major classes: capa peptides, pyrokinins (PK) and ecdysis triggering hormone (ETH). Capa peptides may be defined by a characteristic C-terminus FXPRVamide.

The second family, the pyrokinins (PK), feature a characteristic C-terminus FXPRLamide and belong to the FXPRLaminde (pyrokinin/PBAN) family and the PRXamide superfamily (Altstein et al. 2013). First identified in the cockroach Leucophaea maderae, PK was found to be myotropic, activating the cockroach hindgut (Holman et al.
1986). However, the subsequent isolation of PKs in other invertebrates has led to some confusion over nomenclature with peptides featuring the characteristic C-terminus FXPRLamide being named after their functions, e.g. pheromone biosynthesis-activating neuropeptides (PBAN) and diapause hormone (DH), which are N-terminally extended pyrokinins found primarily in Lepidoptera, with specific neuronal and hormonal functions (DiNER; Yeoh et al. 2017). Pyrokinins are known to have roles in insect development, mating, muscle contraction and tannin (Altstein et al. 2013).

The final group, the insect kinins are multifunctional neuropeptides sharing a conserved C-terminal pentapeptide motif FX ${ }^{1} \mathrm{X}^{2} \mathrm{WGamide}$, where $\mathrm{X}^{1}$ can be Histidine, Asparagine, Serine or Tyrosine, and $X^{2}$ can be Serine, Proline or Alanine (Holman et al. 1999). Since their discovery, kinins have been identified in most insects including $D$. suzukii (Terhzaz et al. 2017) with the exception of Coleoptera (Halberg et al. 2015), and with roles in myostimulation (Holman et al. 1987; Schoofs et al. 1993), fluid secretion by the Malpighian tubules (Coast et al. 1990; Radford et al. 2002; Dow 2009; Coast et al. 2011), the release of digestive enzymes (Harshini et al. 2002, 2003) and inhibition of larval weight gain (Nachman et al. 2003; Seinsche et al. 2000).

In Drosophila, tolerance to cold and desiccation stress is modulated by gene expression for key physiological responses including ion transport, carbohydrate metabolism, antioxidants, immunity, signalling and gene expression pathways (Davies et al. 2014; Terhzaz et al. 2015). Recent work has also identified neuroendocrine signalling by kinin and capa peptides as a control mechanism of environmental stress tolerance, with the Malpighian tubules representing the primary target of neuropeptide action (Terhzaz et al. 2012, 2015, 2017; Cannell et al. 2016). Here, capa acts to increase intracellular calcium $\left(\mathrm{Ca}^{2+}\right)$, triggering a nitric oxide/cGMP signalling pathway in the tubule's principal cells (Rosay et al. 1997; Kean et al. 2002), whilst kinin acts on tubule stellate cells to elevate intracellular calcium $\left(\mathrm{Ca}^{2+}\right)$ and chloride shunt conductance (Terhzaz et al. 1999; Radford et al. 2002; Cabrero et al. 2014). Unlike capa and kinin, PKs are not known to have roles in environmental stress tolerance. However, cross-activity of PK analogues has been observed, with analogues displaying activity on recombinant capa receptors of Tribolium castaneum (Jiang et al. 2014, 2015). For this reason, selected PK analogues have been included in the current study into Drosophila desiccation and thermal stress, notably 1895 (Table 1) which exhibited agonist activity, and 1896 and 1902 (Table 1) which exhibited antagonist activity, on the T. castaneum TcCAPAr (Jiang et al. 2015). Furthermore, the addition of hydrophobic moieties to the N-terminus of PRXamide analogues, as exhibited by analogues 1895, 1896 and 1902 (Table 1), results in greater in vivo biostability (Zhang et al. 2011). Analogues 2089 and 2129 (Table 1) were subsequently designed and 
Table 1 CAP2b, pyrokinin and kinin analogues

\begin{tabular}{ll}
\hline Code & Structure \\
\hline CAP2b/PK & \\
1895 & 2Abf-Suc-FGPRLa \\
1896 & 2Abf-Suc-FTPRIa \\
1902 & 2Abf-Suc-FKPRLa \\
2089 & 2Abf-Suc-FTPRVa \\
2129 & 2Abf-Suc-ATPRIa \\
Kinin & \\
1728 & [Aib]FF[Aib]WGa \\
2139 & FF[Aib]WGa \\
$2139-A C$ & Ac-FF[Aib]WGa \\
\hline
\end{tabular}

Modifications are shown in bold

synthesised as second-generation analogues of 1895, 1896 and 1902 to be evaluated in the current study. For the purpose of this study, these peptide analogues belonging to the PRXamide superfamily will be collectively referred to as 'CAP2b/PK'.

In addition to the Cap2b/PK analogues, kinin analogues were included in the current study due to their role in environmental stress control. However, insect kinins are subject to rapid biological degradation by peptidases. Incorporation of the $\alpha$-amino isobutyric acid (Aib) at the third position of the insect kinin active core has been shown to protect the primary hydrolysis site from tissue-bound peptidase (Nachman et al. 1997a, b, 2002; Taneja-Bageshwar et al. 2006, 2009). Incorporation of a second Aib residue adjacent to the secondary peptidase hydrolysis site further enhances biostability (Nachman et al. 2002). Indeed, kinin analogues incorporating sterically bulky Aib residues adjacent to the primary and secondary hydrolysis sites have been shown to retain potent activity on receptors of the southern cattle tick, Rhipicephalus (Boophilus) microplus (Taneja-Bageshwar et al. 2006, 2009), and the dengue vector, the mosquito Aedes aegypti (Taneja-Bageshwar et al. 2006, 2009). For this reason, three biostable Aib analogues of the insect kinins 1728, 2139 and 2139-Ac were evaluated in the current study (Table 1).

The current study therefore aimed to elucidate the effect of biostable CAP2b/PK and kinin analogues on the stress tolerance of the pest insect $D$. suzukii and the closely related non-pest species $D$. melanogaster. Biostable analogues (Nachman 2009) were tested ex vivo for their physiological role in modulating fluid secretion via the Malpighian tubules and in vivo for their effect on desiccation, starvation and cold stress tolerance. To add additional validity to the screening process, promising analogues were further tested in vitro for their ability to trigger a $\mathrm{Ca}^{2+}$ signalling response in Drosophila S2 cells heterologously expressing prospective target receptors of the tested peptide analogues.

\section{Material and methods}

\section{Drosophila rearing}

Drosophila melanogaster wild-type flies were obtained from Bloomington Stock Centre and maintained on a standard Drosophila medium at $22{ }^{\circ} \mathrm{C}, 45-55 \%$ relative humidity and a 12:12 h light: dark photoperiod. D. suzukii flies were reared on standard blueberry-cornmeal agar medium, at $26^{\circ} \mathrm{C}, 60 \%$ humidity with a $12: 12 \mathrm{~h}$ light: dark photoperiod (Terhzaz et al. 2017). Adult Drosophila of both sexes were used in all experiments, 6-7 days after eclosion.

\section{Neuropeptide analogue synthesis}

The synthesis of neuropeptide analogues has been previously described as follows: CAP2b/PK analogues (displaying prior cross-talk with the capa receptor) 1895 and 1902 (Zhang et al. 2011; Jiang et al. 2015); 1896 (Jiang et al. 2015), 2089 and 2129 (using the method described in Zhang et al. 2011); kinin analogues 1728, 2139 and 2139-Ac (Taneja-Bageshwar et al. 2006, 2009). Analogues were purified and identity confirmed as detailed in Alford et al. (2019). The structures of the biostable analogues are displayed in Table 1.

\section{Fluid secretion assay}

Prior to in vivo screening, peptide analogues were first tested ex vivo for efficacy via a Ramsay fluid secretion assay for Drosophila Malpighian tubules (Dow et al. 1994; Terhzaz et al. 2017). Capa-1 at $10^{-5} \mathrm{M}$ stimulates fluid secretion in D. melanogaster tubules (Kean et al. 2002) and calcium increase via the capaR (Terhzaz et al. 2012), but at levels which are not significantly different from $10^{-7} \mathrm{M}$. For this reason, analogues were first tested at a concentration of $1 \times 10^{-5} \mathrm{M}$ to efficiently rule out those analogues which failed to impact Malpighian tubule fluid secretion. Analogues that stimulated fluid secretion at $10^{-5} \mathrm{M}$ were subsequently tested at lower concentrations down to $1 \times 10^{-9} \mathrm{M}$. Briefly, Malpighian tubules from 6-d-old adult D. melanogaster and D. suzukii flies of mixed sex were isolated in Schneider's medium and suspended in a $9 \mu \mathrm{l}$ drop of a 1:1 mixture of Schneider's medium: Drosophila saline. Male and female, posterior and anterior tubules were used interchangeably and grouped together due to showing no prior significant difference in secretion rate, with 10-15 secreting tubules per condition. Basal secretion rates were measured every $10 \mathrm{~min}$ for a period of $30 \mathrm{~min} .1 \mu \mathrm{l}$ of neuropeptide analogue $\left(1 \times 10^{-4} \mathrm{M}\right.$ stock solution) was then added to each well, resulting in a final concentration of $1 \times 10^{-5} \mathrm{M}$. Secretion rates were subsequently measured for 
an additional $30 \mathrm{~min}$. Resultant data were analysed using a $t$ test or Mann-Whitney $U$ test to compare pre-stimulated basal time points (pooled 10-30 min) to each post-stimulated secretion time point. All analogues which stimulated fluid secretion at the supraphysiological dose of $1 \times 10^{-5} \mathrm{M}$ were subsequently tested at increasingly lower concentrations down to $1 \times 10^{-9} \mathrm{M}$ to test for differential sensitivity of the Malpighian tubules.

\section{Microinjection of Drosophila}

Native neuropeptides were diluted in Drosophila injection saline (Terhzaz et al. 2015) to $1 \times 10^{-5} \mathrm{M}$. Neuropeptide analogues were diluted in Drosophila injection saline to the following concentrations : kinin analogues $1728\left(2.5 \times 10^{-5} \mathrm{M}\right)$, $2139\left(3.5 \times 10^{-5} \mathrm{M}\right), 2139-\mathrm{Ac}\left(3.5 \times 10^{-5} \mathrm{M}\right) ; \mathrm{CAP} 2 \mathrm{~b} / \mathrm{PK}$ analogues $1895\left(3.5 \times 10^{-5} \mathrm{M}\right), 1896\left(3.5 \times 10^{-5} \mathrm{M}\right), 1902$ $\left(3.5 \times 10^{-5} \mathrm{M}\right), 2089\left(3.9 \times 10^{-5} \mathrm{M}\right), 2129\left(2.0 \times 10^{-5} \mathrm{M}\right)$. Neuropeptide solutions were administered to test flies at a sex-adjusted injection volume of $69 \mathrm{~nL}$ for females and $41 \mathrm{~nL}$ for males (Terhzaz et al. 2015). Injections were performed using a Nanoject II Auto-Nanoliter Injector (Drummond Scientific Company, Broomall, Pennsylvania). Flies were injected in the thoracic segment below the left haltere. A vehicle control was set up on each treatment day. For this, control flies were injected with $69 \mathrm{~nL}$ or $41 \mathrm{~nL}$ of injection saline and exposed to identical conditions as flies receiving the neuropeptide treatment. Amaranth dye (Sigma; A1016) was added to all injected media to assist in visualising the success of an injection (i.e. to ensure that fluid was injected below the insect cuticle). Neuropeptide-treated and vehicle control flies were subsequently used in the stress bioassays detailed below.

\section{Desiccation tolerance bioassay}

Drosophila suzukii and D. melanogaster 6-d-old male and female flies were treated with a neuropeptide analogue or injection saline (vehicle control) via microinjection as detailed above. Following injection, flies were placed in groups of ten in $30 \mathrm{~mL}$ empty vials (no food or water) or vials containing $1 \%$ agar (no food) and the open end of the tube sealed with a cotton plug (buzzplug, Scientific Laboratory Supplies or Fly stuff, Flugs (49-103) (Bemis, NA)). Vials containing $1 \%$ agar provided flies with a water source and acted as the experimental control group. Surviving flies were counted every $3-4 \mathrm{~h}$ until no living flies remained. All experiments were run in triplicate with 20-30 flies for each species/sex/neuropeptide treatment combination. Survival data were subsequently analysed using a log-rank (Mantel-Cox) test in GraphPad Prism version 7.0.

\section{Cold tolerance bioassay}

\section{Calculation of discriminating temperatures}

The method for peptide analogue screening was adapted from the methodology commonly used to detect the presence of a rapid cold hardening response in insects (Lee et al. 1987). Here, variation in survival is compared between treatment groups at a predetermined 'discriminating temperature' (e.g. Powell and Bale 2005). To calculate a discriminating temperature, survival curves were first established for male and female $D$. suzukii and $D$. melanogaster to enable calculation of species-specific discriminating temperatures for subsequent neuropeptide testing. For this, adults of $D$. suzukii and D. melanogaster were selected at 6-d-old post-eclosion and exposed to a range of low temperatures $\left(-10{ }^{\circ} \mathrm{C}\right.$ to $-2{ }^{\circ} \mathrm{C}$ at $1{ }^{\circ} \mathrm{C}$ intervals) using a direct plunge method (Sinclair and Chown 2006; Terblanche et al. 2008). Temperature ranges were selected to encompass $0-100 \%$ mortality. For each temperature treatment, 30 adults of each sex and each species were anesthetised briefly with $\mathrm{CO}_{2}$ and placed within plastic $0.5 \mathrm{~mL}$ Eppendorf tubes at densities of ten adults per tube, which, in turn, were placed within a glass boiling tube held within an alcohol bath (Haake G50 and PC200; Thermo Scientific, Germany) preset to the desired temperature. Pieces of cotton wool were used to stopper the boiling tubes to limit air circulation and to ensure a more stable internal temperature within the tubes. Adults were held at the desired exposure temperature for $1 \mathrm{~h}$. Following exposure, adults were allowed to recover at the culture temperature in vials containing a food source and survival was assessed after $48 \mathrm{~h}$. The procedure was repeated for each exposure temperature. A total of 270 male $D$. melanogaster, 270 female $D$. melanogaster, 240 male $D$. suzukii and 240 female D. suzukii were used to independently assess the cold tolerance of each species.

Survival data were analysed by Probit analysis in MINITAB, version 17 (Minitab Inc., State College, Pennsylvania), and the $\mathrm{LT}_{30}$ (the lethal temperature resulting in 30\% mortality of a test population) was elucidated for each species. The $\mathrm{LT}_{30}$ was chosen to act as a discriminating temperature for subsequent neuropeptide testing since it enabled detection of directional effects of subsequent neuropeptide treatment, but primarily in the direction of interest, i.e. which neuropeptides significantly increased mortality in the species of interest. A separate discriminating temperature was calculated for males and females of each species to ensure that exposure to the discriminating temperature posed a comparable level of thermal stress for each species/sex treatment group. 
Neuropeptide treatment and testing at the discriminating temperature

Individuals of D. suzukii and D. melanogaster were selected at 5-d-old post-eclosion and treated with neuropeptide analogues using the microinjection method detailed above. Following microinjection treatment, individuals were returned to vials containing food at densities of approximately 20-30 per vial and allowed to recover for $24 \mathrm{~h}$ at the culture temperature. Following the 24-h recovery period, adults of $D$. suzukii and D. melanogaster were cold shocked at the discriminating temperature following the same protocol as used to establish the discriminating temperature. Statistical analyses were performed using R software (R Development Core Team 2013). A generalised linear model (GLM) with binomial family was fitted to survival data with analogue 'Treatment' (peptide analogue), treatment 'Type' (test vs. control) and analogue treatment $\times$ treatment type interaction as factors.

\section{Measurements of analogue-induced intracellular $\mathrm{Ca}^{2+}$ signalling response}

Promising analogues from in vivo assays were taken forward and tested in vitro for an ability to trigger an intracellular $\mathrm{Ca}^{2+}$ signalling response in Drosophila S2 cells (Terhzaz et al. 2012). Transient transfection was performed with Effectene Transfection Reagent (Qiagen) using $1 \mu \mathrm{g}$ of DNA of inducible pMT-CapaR and pMT-Apoaequorin expression vectors prepared according to manufacturer's instructions. Cells were plated in 6 -well plates $\left(1 \times 10^{6}\right.$ cells $\left./ \mathrm{mL}\right)$ and were incubated with the transfection mixture for $24 \mathrm{~h}$ before adding $\mathrm{CuSO}_{4}$ (final concentration of $500 \mu \mathrm{M}$ ) to the cell culture $(3 \mathrm{~mL})$ for $48 \mathrm{~h}$ to induce capaR and Apoaequorin protein expression. Transfected S2 cells were harvested and incubated with $2.5 \mu \mathrm{M}$ coelenterazine in the dark at room temperature for $1 \mathrm{~h}$ (Radford et al. 2002). Approximately 25,000 cells were subsequently placed in $175 \mu \mathrm{L}$ Schneider's medium containing 10\% FCS within a $5 \mathrm{~mL}$ Röhren tube (Sarstedt, Germany). Bioluminescence was recorded every $0.1 \mathrm{~s}$ using a Lumat LB 9507 luminometer (Berthold Technologies). Of a peptide analogue, $25 \mu \mathrm{L}$ of a peptide analogue was applied to a final concentration of $10^{-7} \mathrm{M}$. Peptides were applied via the reagent rapid injectors of the Lumat LB 9507 luminometer into the aequorin-transfected $\mathrm{S} 2$ cell samples. This enables rapid and continuous recording of luminescence of the intracellular capa-induced $\mathrm{Ca}^{2+}$ signalling response (Rosay et al. 1997; Terhzaz et al. 2012). CAP2b (and capa) causes a rapid $(<100 \mathrm{~ms})$ rise of $\left[\mathrm{Ca}^{2+}\right] i$ that remains significantly above background for $90 \mathrm{~s}$. The detection limit of the instrument has a time resolution of $100 \mathrm{~ms}$; it may be that the actual response is even more rapid (Rosay et al. 1997). Accurate quantification of calcium levels at any point in the experiment requires the total available luminescence (i.e. the amount of reconstituted aequorin) to be known, since only a small fraction is used during the experiment (Cobbold and Rink 1987). Therefore, after a 5 -min recording period, tissues were disrupted in $200 \mu \mathrm{L}$ lysis solution (1\% (v/v) Triton X-100, $\left.100 \mathrm{mM} \mathrm{CaCl}_{2}\right)$, causing discharge of the remaining aequorin and allowing estimation of the total amount of aequorin in the sample by integration of total counts. The $\left[\mathrm{Ca}^{2+}\right]$ concentration was subsequently calculated as previously described in Rosay et al. (1997).

\section{Results}

\section{Fluid secretion assay}

Ramsay secretion assays were performed on both $D$. melanogaster and D. suzukii, (Fig. 1). All three kinin analogues (1728, 2139 and 2139-Ac) tested at a concentration of $\times 10^{-5} \mathrm{M}$ acted to significantly increase secretion rate (Fig. 1a-c). Of the CAP2b/PK neuropeptide analogues tested to a final concentration of $\times 10^{-5} \mathrm{M}$, four had no effect on Malpighian tubule secretion of either species: 1896, 1902, 2089 and 2129. CAP2b/PK analogue 1895 caused a small but significant decrease in the fluid secretion of $D$. suzukii (Fig. 1d), but not in D. melanogaster.

Lower concentrations of the three kinin neuropeptide analogues were tested to determine fluid secretion response of the Malpighian tubules of D. melanogaster and D. suzukii to these analogues. For analogue 1728, a final concentration of $2.5 \times 10^{-7} \mathrm{M}$ failed to elicit a response in the fluid secretion rate of the Malpighian tubules of either species (data not shown). Application of 2139 at $3.5 \times 10^{-7} \mathrm{M}$ caused a significant increase in the fluid secretion rate of the Malpighian tubules of $D$. suzukii but not D. melanogaster (Fig. 1e). Application of 2139 at the lower concentration of $3.5 \times 10^{-8} \mathrm{M}$ failed to elicit a response in D. suzukii (data not shown). Analogue 2139-Ac caused a significant increase in both species at $3.5 \times 10^{-7} \mathrm{M}$ (Fig. 1f), but failed to do so at $3.5 \times 10^{-9} \mathrm{M}$ (data not shown).

\section{Desiccation stress}

Results of the desiccation bioassay are displayed in Table 2, with selected survival curves shown in Fig. 2. Of the tested analogues, kinin analogue 2139 and CAP2b/PK analogue 1896 acted to significantly reduce survival under conditions of desiccation stress for $D$. melanogaster, although the effect was not consistent between the sexes. Here, 2139 significantly impacted only female survival (median survival: control 27.0 h, treatment 21.0 h) (Fig. 2a). 1896 significantly impacted only male survival, although median survival was 

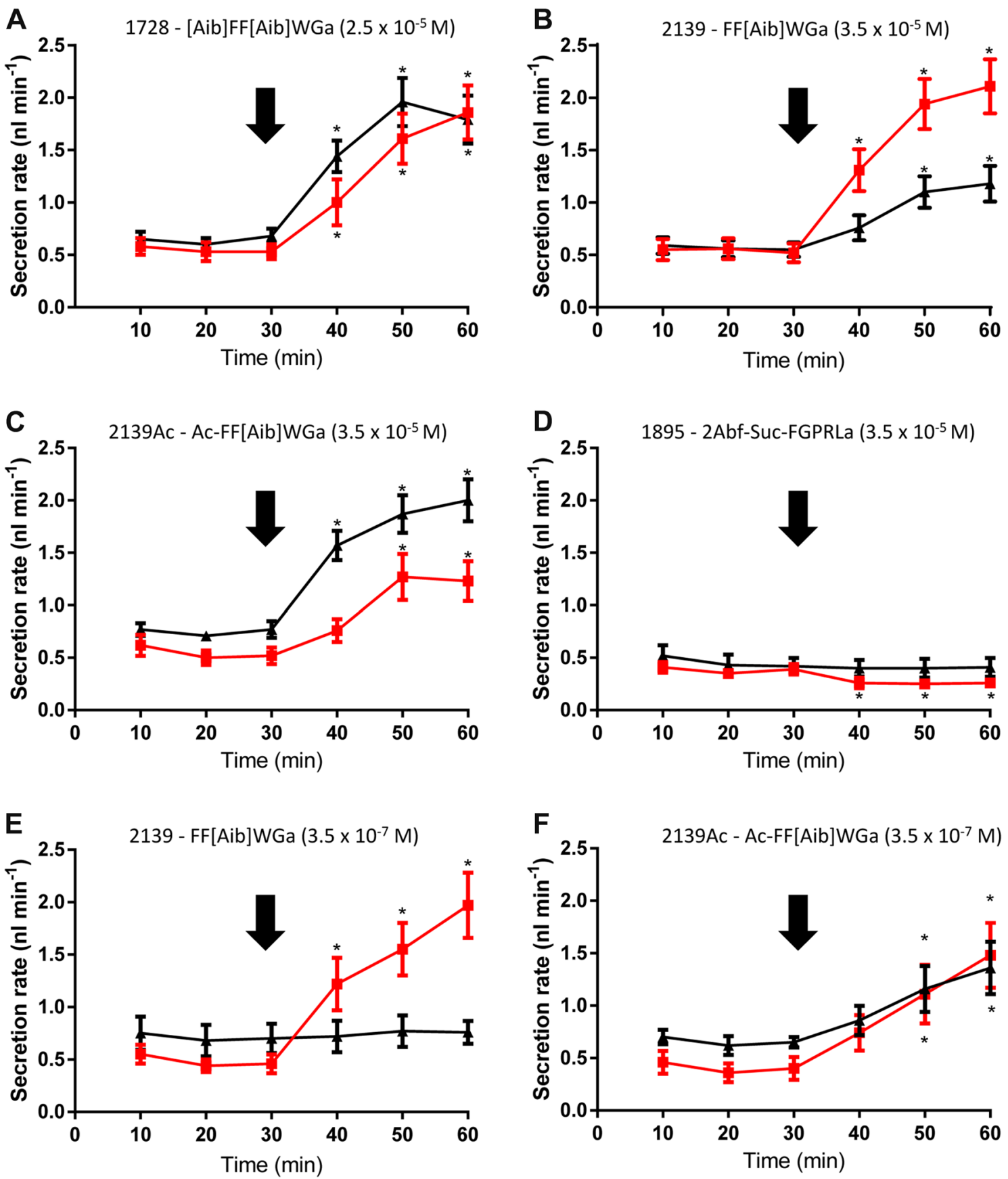

Fig. 1 Effects of neuropeptide analogues on fluid secretion rates of D. melanogaster (black) and D. suzukii (red) Malpighian tubules. Data show the response of tubule fluid secretion rate to a kinin $1728\left(2.5 \times 10^{-5} \mathrm{M}\right)$, b kinin $2139\left(3.5 \times 10^{-5} \mathrm{M}\right)$, c kinin 2139-

Ac $\left(3.5 \times 10^{-5} \mathrm{M}\right), \mathbf{d}$ CAP2b/PK $1895\left(3.5 \times 10^{-5} \mathrm{M}\right)$, e kinin 2139 $\left(3.5 \times 10^{-7} \mathrm{M}\right)$ and $\mathbf{f}$ kinin $2139-\mathrm{Ac}\left(3.5 \times 10^{-7} \mathrm{M}\right)$. Tubules were stimulated with the analogue at $30 \mathrm{~min}$, as indicated by the black arrow. Data are presented as mean $\pm \mathrm{SEM} ; p<0.05$

identical between the control and treatment group, (median survival: control $14.0 \mathrm{~h}$, treatment $14.0 \mathrm{~h}$ ) (Fig. 2b). Interestingly, 2139 had no effect on the desiccation tolerance of $D$. suzukii (Fig. 2a), and 1896 acted to significantly increase the survival of female $D$. suzukii (median survival: control $20.5 \mathrm{~h}$, treatment $23.5 \mathrm{~h}$ ) (Fig. 2b). CAP2b/PK analogues 1895 and 1902 (Fig. 2b) significantly increased survival of

both male and female $D$. suzukii under desiccation stress (1895 median survival: male control $8.0 \mathrm{~h}$, treatment $10.0 \mathrm{~h}$; female control $16.0 \mathrm{~h}$, treatment $25.5 \mathrm{~h})(1902$ median survival: male control $7.0 \mathrm{~h}$, treatment $14.0 \mathrm{~h}$; female control $17.0 \mathrm{~h}$, treatment $21.0 \mathrm{~h}$ ), although showed no effect on D. melanogaster survival. Analogue 2129 significantly improved female D. melanogaster (median survival control: 
Table 2 (a) CAP2b, pyrokinin and kinin analogue impact on desiccation tolerance of male and female D. melanogaster and D. suzukii. (b) Experimental control flies were subjected to a starvation stress in the presence of a water source (1\% agar). Survival is shown as median survival $(h) \pm$ interquartile range

\begin{tabular}{|c|c|c|c|c|c|c|}
\hline \multirow[b]{2}{*}{ Peptide } & \multicolumn{6}{|c|}{ Desiccation } \\
\hline & Male & $\begin{array}{l}\text { Median survival } \pm \mathrm{IQR}(\mathrm{h}) \\
\text { vehicle controlltreatment }\end{array}$ & & Female & $\begin{array}{l}\text { Median survival } \pm \mathrm{IQR}(\mathrm{h}) \\
\text { vehicle controlltreatment }\end{array}$ & \\
\hline \multicolumn{7}{|c|}{ D. melanogaster } \\
\hline Kinin & & & $p$ & & & $p$ \\
\hline 1728 & & $22.0 \pm 3.0 \mid 22.0 \pm 0.0$ & 0.579 & & $22.0 \pm 2.0 \mid 22.0 \pm 0.0$ & 0.004 \\
\hline 2139 & & $20.0 \pm 3.0 \mid 20.5 \pm 3.0$ & 0.614 & & $27.00 \pm 23.3121 .0 \pm 6.0$ & $<0.001$ \\
\hline 2139-AC & & $11.0 \pm 13.0111 .0 \pm 10.0$ & 0.488 & & $8.0 \pm 14.3116 .0 \pm 13.0$ & 0.024 \\
\hline \multicolumn{7}{|l|}{$\mathrm{CAP} 2 \mathrm{~b} / \mathrm{PK}$} \\
\hline 1895 & & $18.0 \pm 9.0 \mid 18.0 \pm 9.1$ & 0.082 & & $29.5 \pm 7.0131 .5 \pm 12.0$ & 0.113 \\
\hline 1896 & & $14.0 \pm 5.0 \mid 14.0 \pm 4.0$ & 0.016 & & $25.0 \pm 9.0 \mid 25.0 \pm 14.8$ & 0.573 \\
\hline 1902 & & $19.0 \pm 14.0 \mid 19.0 \pm 7.8$ & 0.136 & & $33.0 \pm 15.0129 .0 \pm 12.0$ & 0.228 \\
\hline 2089 & & $25.0 \pm 12.5133 .0 \pm 11.0$ & 0.375 & & $39.0 \pm 14.0137 .50 \pm 18.0$ & 0.655 \\
\hline 2129 & & $19.0 \pm 15.8119 .0 \pm 15.0$ & 0.879 & & $14.0 \pm 12.0127 .00 \pm 15.0$ & $<0.001$ \\
\hline \multicolumn{7}{|l|}{ D. suzukii } \\
\hline Kinin & & & $p$ & & & $p$ \\
\hline 1728 & & $6.0 \pm 3.016 .0 \pm 6.3$ & 0.939 & & $20.0 \pm 0.0 \mid 20.0 \pm 0.0$ & 0.802 \\
\hline 2139 & & $7.0 \pm 17.018 .0 \pm 17.0$ & 0.198 & & $22.0 \pm 0.0 \mid 22.0 \pm 0.0$ & 0.832 \\
\hline 2139-AC & & $3.0 \pm 4.0016 .0 \pm 3.0$ & $<0.001$ & & $7.5 \pm 9.0119 .0 \pm 4.0$ & $<0.001$ \\
\hline \multicolumn{7}{|l|}{$\mathrm{CAP} 2 \mathrm{~b} / \mathrm{PK}$} \\
\hline 1895 & & $8.0 \pm 7.0110 .0 \pm 8.0$ & 0.010 & & $16.0 \pm 13.5125 .50 \pm 6.3$ & $<0.001$ \\
\hline 1896 & & $8.5 \pm 4.018 .5 \pm 4.0$ & 0.706 & & $20.5 \pm 7.0123 .5 \pm 9.0$ & 0.009 \\
\hline 1902 & & $7.0 \pm 0.8114 .0 \pm 7.0$ & $<0.001$ & & $17.0 \pm 7.8121 .0 \pm 10.0$ & 0.034 \\
\hline 2089 & & $13.0 \pm 7.6115 .0 \pm 7.8$ & 0.291 & & $23.0 \pm 11.0 \mid 23.0 \pm 8.0$ & 0.550 \\
\hline 2129 & & $5.0 \pm 6.016 .5 \pm 15.0$ & 0.029 & & $17.0 \pm 5.0 \mid 24.0 \pm 7.0$ & $<0.001$ \\
\hline
\end{tabular}

(b)

\begin{tabular}{|c|c|c|c|c|c|c|}
\hline \multirow[b]{2}{*}{ Peptide } & \multicolumn{6}{|c|}{ Starvation control } \\
\hline & Male & $\begin{array}{l}\text { Median survival } \pm \mathrm{IQR}(\mathrm{h}) \\
\text { vehicle controlltreatment }\end{array}$ & & Female & $\begin{array}{l}\text { Median survival } \pm \mathrm{IQR}(\mathrm{h}) \\
\text { vehicle controlltreatment }\end{array}$ & \\
\hline \multicolumn{7}{|c|}{ D. melanogaster } \\
\hline Kinin & & & $p$ & & & $p$ \\
\hline 1728 & & $47.0 \pm 0.0 \mid 47.0 \pm 16.5$ & 0.177 & & $74.0 \pm 21.8174 .0 \pm 6.0$ & 0.283 \\
\hline 2139 & & $47.0 \pm 0.0 \mid 47.0 \pm 0.0$ & 0.304 & & *|* & NA \\
\hline 2139-AC & & $39.0 \pm 11.5135 .0 \pm 15.3$ & 0.876 & & $* \mid *$ & NA \\
\hline \multicolumn{7}{|l|}{$\mathrm{CAP} 2 \mathrm{~b}$} \\
\hline 1895 & & $64.5 \pm 33.8176 .5 \pm 24.3$ & 0.789 & & $97.0 \pm 36.31107 .5 \pm 45.5$ & 0.143 \\
\hline 1896 & & $56.0 \pm 14.3175 .0 \pm 26.3$ & 0.008 & & $83.0 \pm 45.81132 .0 \pm 50.0$ & 0.037 \\
\hline 1902 & & $68.0 \pm 28.0162 .0 \pm 22.3$ & 0.219 & & $80.0 \pm 8.5 \mid 80.0 \pm 19.5$ & 0.985 \\
\hline 2019 & & $85.0 \pm 21.3193 .0 \pm 22.0$ & 0.538 & & $142.0 \pm 23.01127 .0 \pm 39.0$ & 0.102 \\
\hline 2129 & & $53.0 \pm 18.5163 .0 \pm 26.3$ & 0.191 & & $71.0 \pm 23.8188 .0 \pm 55.3$ & 0.058 \\
\hline \multicolumn{7}{|l|}{ D. suzukii } \\
\hline Kinin & & & $p$ & & & $p$ \\
\hline 1728 & & $30.0 \pm 13.0 \mid 25.0 \pm 5.8$ & 0.734 & & $48.5 \pm 27.0 \mid 48.0 \pm 6.0$ & 0.035 \\
\hline 2139 & & $23.0 \pm 6.0 \mid 22.0 \pm 4.8$ & 0.282 & & $49.0 \pm 0.0149 .0 \pm 0.0$ & 0.737 \\
\hline 2139-AC & & $26.0 \pm 7.0 \mid 19.0 \pm 14.0$ & 0.018 & & $* \mid *$ & NA \\
\hline \multicolumn{7}{|l|}{ CAP2b } \\
\hline 1895 & & $34.5 \pm 13.3136 .5 \pm 17.0$ & 0.406 & & $75.5 \pm 33.5178 .5 \pm 12.0$ & 0.899 \\
\hline 1896 & & $33.5 \pm 17.0133 .5 \pm 11.0$ & 0.170 & & $52.5 \pm 13.0157 .5 \pm 61.0$ & 0.476 \\
\hline 1902 & & $32.5 \pm 16.0132 .5 \pm 15.0$ & 0.626 & & $69.0 \pm 21.0166 .0 \pm 15.0$ & 0.675 \\
\hline 2019 & & $52.0 \pm 5.3155 .0 \pm 11.3$ & 0.208 & & $85.0 \pm 34.8185 .0 \pm 21.0$ & 0.321 \\
\hline 2129 & & $32.5 \pm 17.0132 .0 \pm 19.1$ & 0.316 & & $81.5 \pm 34.0179 .0 \pm 26.5$ & 0.811 \\
\hline
\end{tabular}


Table 2 (continued)

Significant effects are shown in bold. Selected survival curves are displayed in Fig. 2

* analysis not possible due to low n numbers
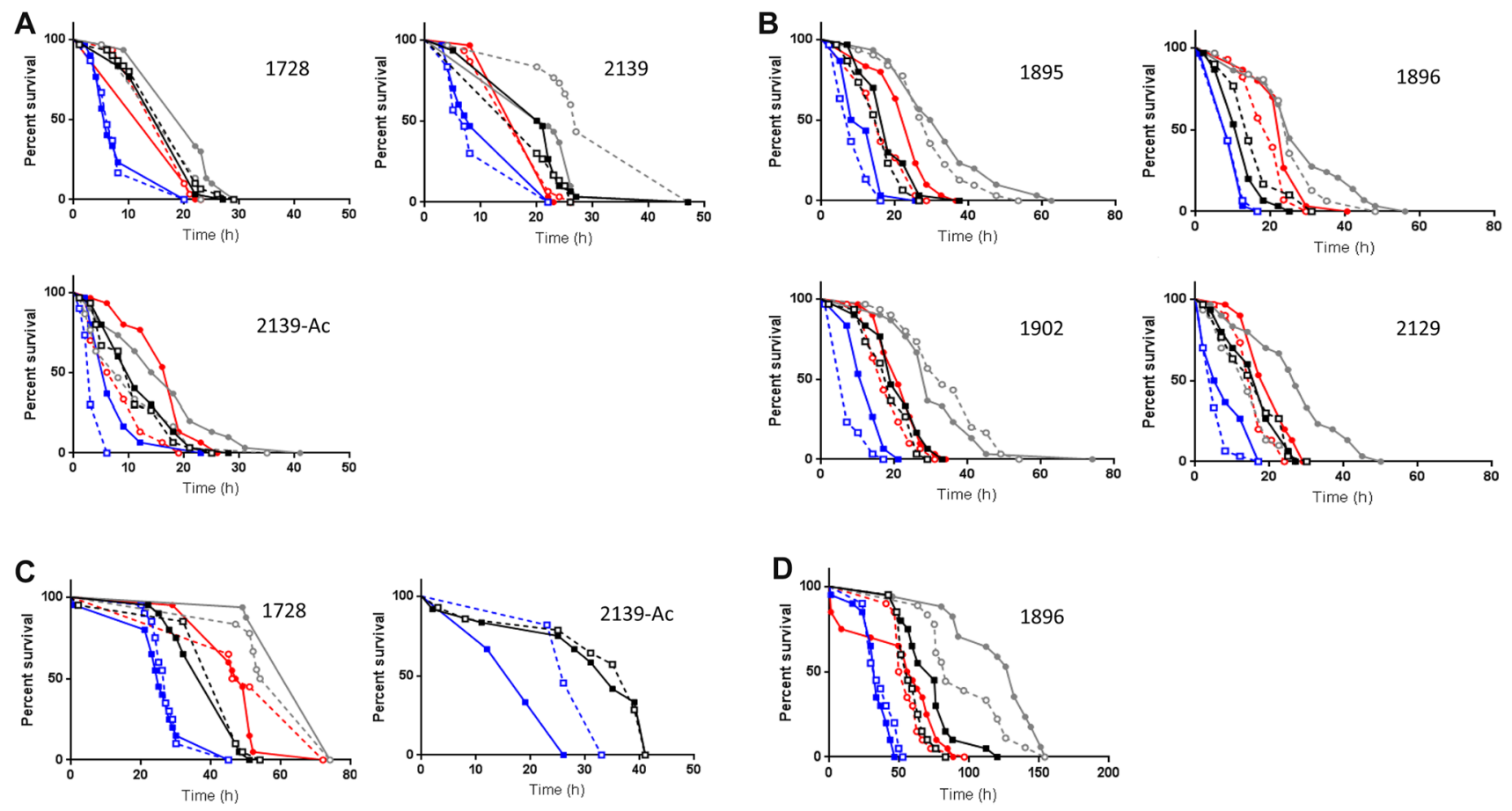

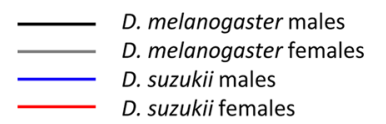

Fig. 2 Selected survival curves of Drosophila melanogaster males (black), D. melanogaster females (grey), D. suzukii males (blue) and D. suzukii females (red) when treated with biostable peptide analogues via microinjection and subjected to either desiccation stress or starvation stress. a Kinin analogue treatment under desiccation stress;

$14.0 \mathrm{~h}$, treatment $27.0 \mathrm{~h}$ ) and both male and female $D$. suzukii survival (median survival: male control $5.0 \mathrm{~h}$, treatment $6.5 \mathrm{~h}$; female control $17.0 \mathrm{~h}$, treatment $24.0 \mathrm{~h}$ ) under desiccation stress, whilst male $D$. melanogaster was unaffected by 2129 (Fig. 2b).

The effect of analogue treatment under the experimental control condition of starvation stress in the presence of a water source ( $1 \%$ agar) was minimal. Kinin analogue 1728 acted to decrease female $D$. suzukii survival, but with enhanced mortality only occurring after the point of LTime ${ }_{50}$ (i.e. the time taken to kill $50 \%$ of the test population) (median survival 48.5 and $48.0 \mathrm{~h}$ for the control and treatment group, respectively) (Fig. 2c). In contrast, treatment with 2139-Ac decreased male survival under conditions of starvation stress (median survival: control $26.0 \mathrm{~h}$, treatment 19.0 h) (Fig. 2c). The kinin analogues had no significant b CAP2b/PK analogue treatment under desiccation stress; c Kinin analogue treatment under starvation stress; d CAP2b/PK analogue treatment under starvation stress. Treatment groups are indicated by the block line and vehicle control groups by the dashed line

effect on the starvation tolerance of $D$. melanogaster. Of the CAP2b/PK analogues, only 1896 significantly increased survival of both male and female $D$. melanogaster (median survival: male control $56.0 \mathrm{~h}$, treatment $75.0 \mathrm{~h}$; female control $83.0 \mathrm{~h}$, treatment $132.0 \mathrm{~h}$ ) (Fig. 2d). The CAP2b/PK analogues had no significant effect on the starvation tolerance of D. suzukii.

\section{Cold stress}

Survival curves were calculated for D. melanogaster and D. suzukii of both sexes (Fig. 3), and the $\mathrm{LT}_{30}$ (discriminating temperature) was calculated as follows: D. melanogaster females $-6.7^{\circ} \mathrm{C} ;$ D. melanogaster males $-6.8^{\circ} \mathrm{C}$; D. suzukii females $-4.9{ }^{\circ} \mathrm{C}$; and D. suzukii males $-4.5^{\circ} \mathrm{C}$. 
Fig. 3 Survival curves calculated via Probit analysis of $D$. melanogaster (black symbols) and $D$. suzukii (blue symbols) following a 1-h exposure at the desired temperature. For both species, males are indicated by the open symbol and dashed line and females by the solid symbol and the solid line

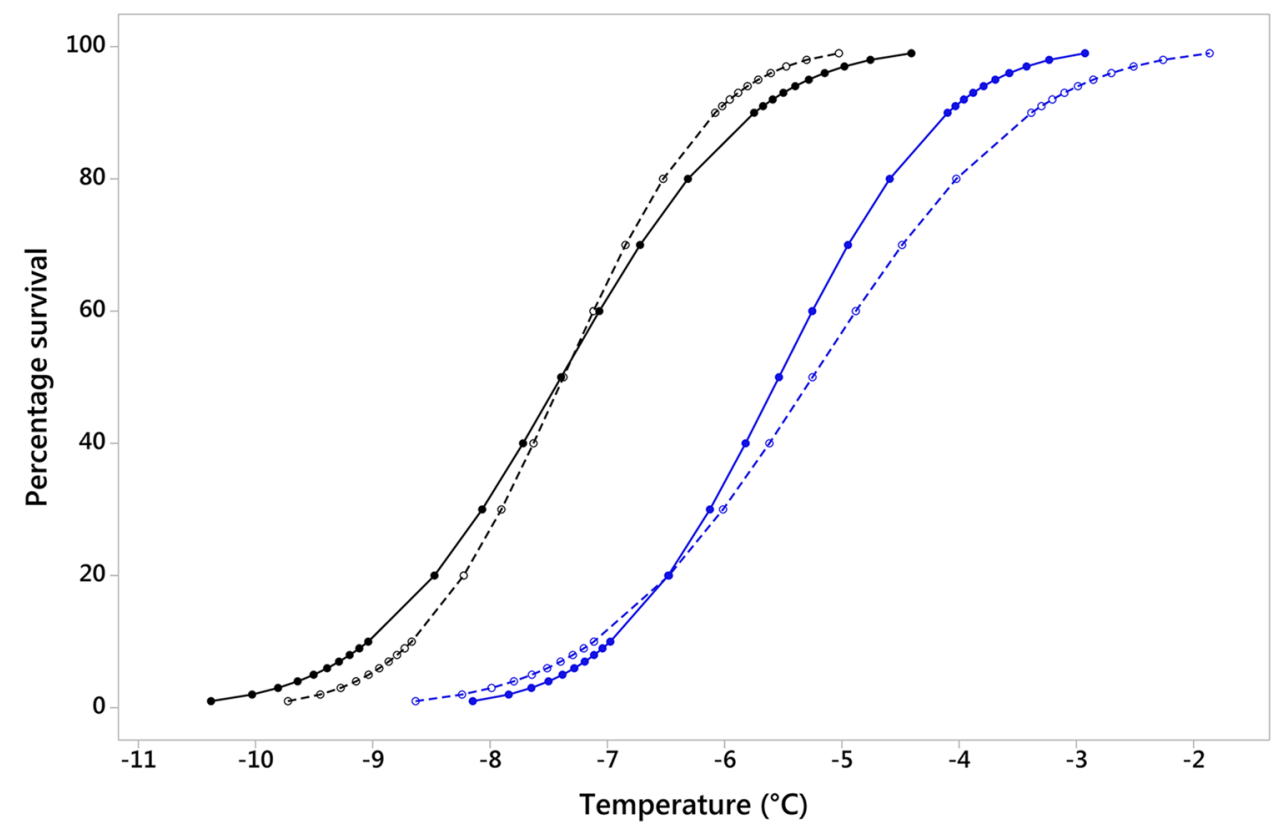

Calculated discriminating temperatures were used for subsequent neuropeptide screening.

Results of the desiccation and starvation bioassay revealed kinin analogues 1728, 2139 and 2139-Ac and CAP2b/PK analogues 1895 and 2129 to be of most interest in eliciting an effect on survival. These neuropeptides were subsequently carried forward for use in the cold stress bioassay.

There was a significant effect of 'Type' (control vs. treatment) on the cold stress survival of D. melanogaster males following cold shock at the discriminating temperature $\left(\mathrm{GLM} \mathrm{DF}=1, \chi^{2}=34.931, p=0.018\right)$, indicating that all analogues are increasing fly survival relative to control groups under conditions of cold stress (Fig. 4). However, there was no effect of the factor 'Treatment' (peptide analogue + associated control) on male D. melanogaster cold stress survival (GLM DF $=4, \chi^{2}=32.714, p=0.696$ ), indicating that all analogues appear equivalent in their effect, with no analogue having a stronger effect than another. In contrast, there was no effect of 'Type' on the cold stress survival of $D$. melanogaster females (GLM DF $=1, \chi^{2}=84.293$, $p=0.723)$, D. suzukii females (GLM DF $=1, \chi^{2}=126.745$, $p=0.729$ ) and the survival of $D$. suzukii males (GLM $\mathrm{DF}=1, \chi^{2}=44.505, p=0.543$ ) when subjected to their discriminating temperature, indicating that peptide analogue treatment failed to impact survival (Fig. 4).

\section{Intracellular $\mathrm{Ca}^{2+}$ response}

Due to eliciting a response in vivo in the desiccation stress assays, the CAP2b/PK analogues were carried forward for in vitro testing for agonistic properties employing transfected Drosophila S2 cells expressing prospective target receptors of the tested peptide analogues. Stimulation of the capa receptor (capaR) with capa-1 results in a biphasic rise in intracellular $\mathrm{Ca}^{2+}$, constituting a rapid primary peak followed by a gradual secondary peak (Fig. 5a) (cf Terhzaz et al. 2012). Stimulation with CAP2b/PK analogue 1895 initiated a $\mathrm{Ca}^{2+}$ response (Fig. 5b), although to a lower magnitude than that observed for the native capa-1 neuropeptide. Stimulation with CAP2b/PK analogues 1896, 1902, 2089 and 2129 failed to initiate a $\mathrm{Ca}^{2+}$ response, suggesting that the analogues are not acting on the capaR (in Fig. 5c, only data for 1896 are shown to represent a non-response). Analogue 1895, which had elicited a stimulatory response against the capaR receptor, failed to initiate a response when tested against the Drosophila pyrokinin 2 (PK2) receptor (Terhzaz et al. 2012) (Fig. 6b). In contrast, 1896 (Fig. 6c) and 1902 (Fig. 6d) both initiated a $\mathrm{Ca}^{2+}$ response when tested on $\mathrm{S} 2$ cells expressing the Drosophila $\mathrm{PK} 2$ receptor, with 1902 producing a response similar in magnitude to the signature biphasic response observed for native pyrokinin (Fig. 6a) (Terhzaz et al. 2012), suggesting that these analogues act as ligands for the PK2 receptor but not capaR.

\section{Discussion}

The neuropeptidergic system offers a promising target for the development of novel, environmentally friendly insecticidal agents and over the last decade has received increasing research attention (Kaczmarek et al. 2010; Smagghe et al. 2010; Zhang et al. 2011; Nachman et al. 2011). Key to the development of peptidomimetic-based insecticides is 


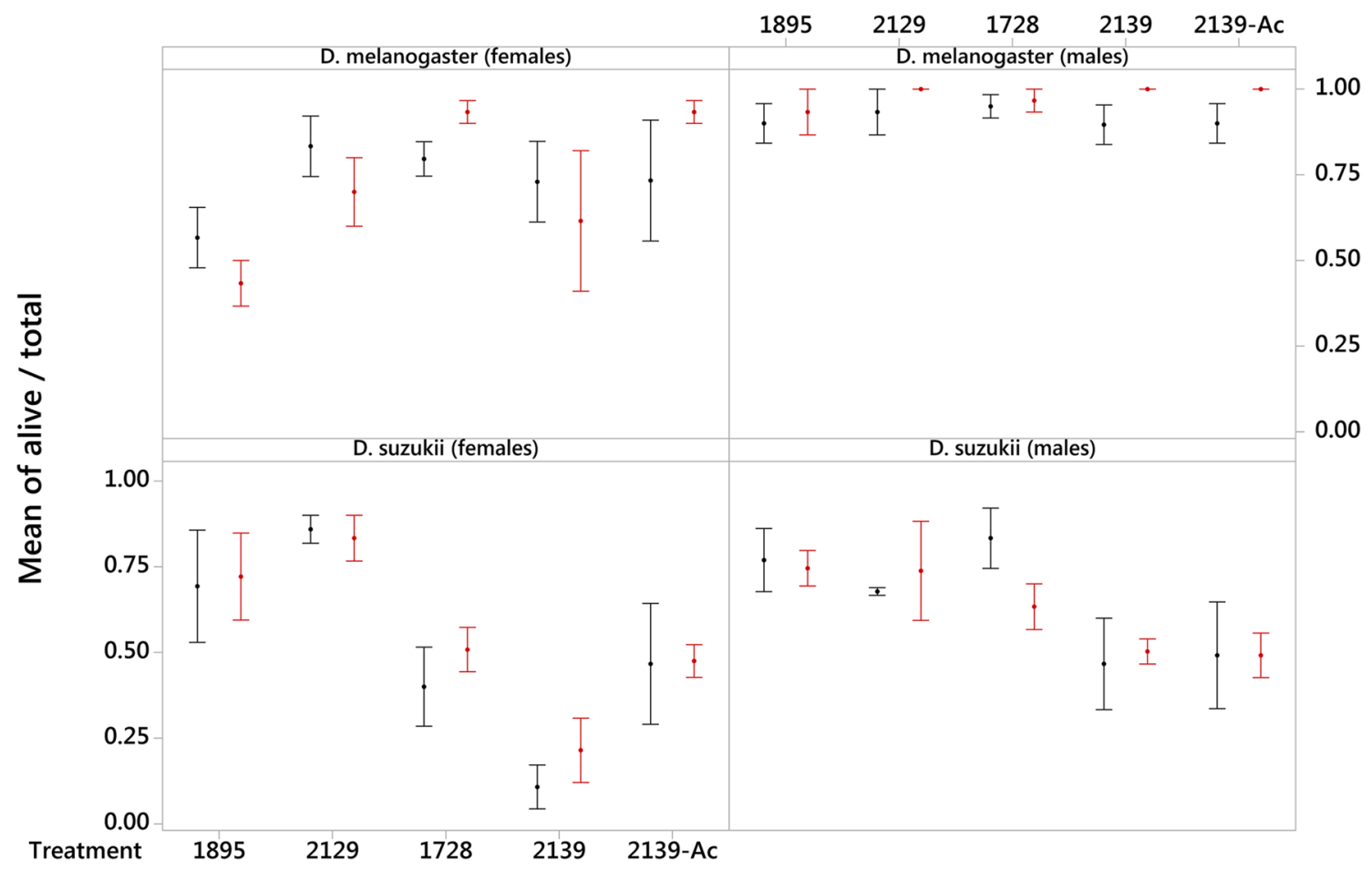

Fig. 4 Mean \pm SE proportion survival of $D$. melanogaster females, $D$. melanogaster males, D. suzukii females and D. suzukii males when treated with biostable peptide analogues (CAP2b/PK: 1895, 2129; kinin: $1728,2139,2139-A c)$ via microinjection and subjected to a discriminating temperature for a 1-h exposure. Control groups are shown in black and peptide treatment groups in red
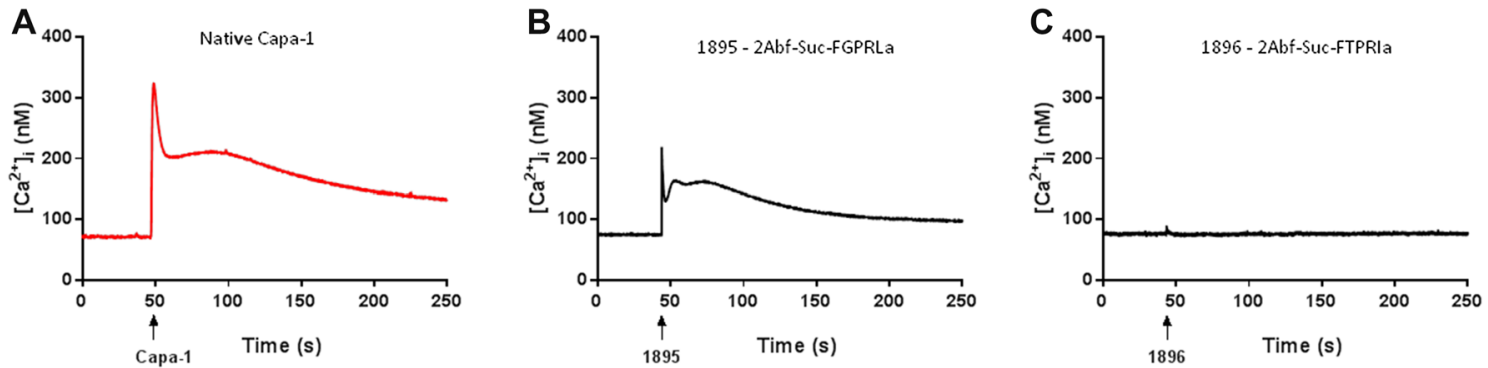

Fig. 5 Capa and biostable analogue-associated calcium signatures. a Typical cytoplasmic $\mathrm{Ca}^{2+}$ response in $\mathrm{S} 2$ cells expressing the capaR and apoaequorin challenged with capa- 1 at a concentration of
$10^{-7}$ M. Cytoplasmic $\mathrm{Ca}^{2+}$ response in $\mathrm{S} 2$ cells when challenged with analogues, b 1895 and c 1896 (representative of a non-response) at a concentration of $10^{-5} \mathrm{M}$

secretion in the Malpighian tubules of D. melanogaster and D. suzukii (Terhzaz et al. 1999, 2017). Furthermore, when testing kinin analogues at increasingly lower concentrations, analogue 2139 stimulated fluid secretion in D. suzukii at concentrations of $\times 10^{-7} \mathrm{M}$, but failed to elicit a response in $D$. melanogaster, suggesting enhanced sensitivity of the $D$. suzukii kinin receptor to analogue 2139. Although all the kinin analogues acted to increase the fluid secretion rate, this did not correlate to a consistent directional effect on D. melanogaster or D. suzukii survival under conditions of desiccation stress. The reason for this is not known, although one explanation may be due to in vivo receptor desensitisation 

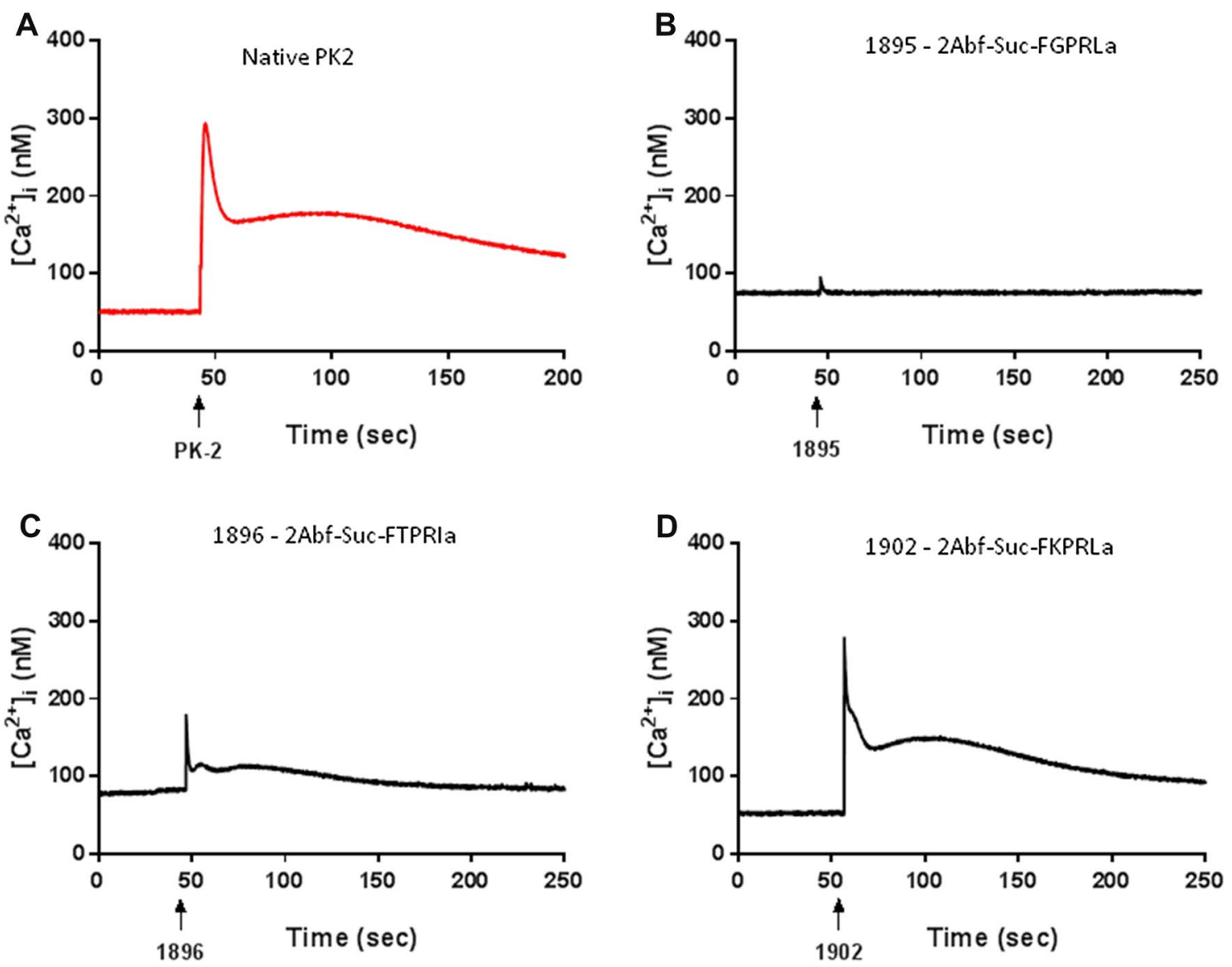

Fig. 6 Pyrokinin and biostable analogue-associated calcium signatures. a Typical cytoplasmic $\mathrm{Ca}^{2+}$ response in $\mathrm{S} 2$ cells expressing the PK2 receptor and apoaequorin challenged with pyrokinin 2 at a con-

under the conditions and time frame of the desiccation stress assay. Furthermore, in the current study, which investigated Drosophila stress tolerance, the Malpighian tubules were the desired target of analogue action. Direct injection of the analogues into the haemolymph was thus chosen as the mode of application to maximise the probability of injected analogues reaching the target organ. However, we cannot exclude analogue action on the Drosophila CNS and further work perturbing the kinin signalling system is required to elucidate this (Zandawala et al. 2018).

In contrast to the kinin analogues, none of the CAP2b/ PK analogues screened significantly affected the rate of fluid secretion in the Malpighian tubules of either D. melanogaster or D. suzukii, with the exception of 1895 which resulted in a small decrease in the secretion of $D$. suzukii tubules. It is known that neuropeptides of the capa family have roles in the stimulation of fluid secretion, acting via elevation of intracellular calcium and activation of the NO-cGMP signalling pathway (Davies et al. 1997; Kean et al. 2002). This failure of most of the screened CAP $2 b$ analogues to impact fluid secretion, either as a diuretic or

centration of $10^{-7} \mathrm{M}$. Cytoplasmic $\mathrm{Ca}^{2+}$ response in S2 cells when challenged with analogues, b 1895, c 1896 and d 1902 at a concentration of $10^{-5} \mathrm{M}$

an anti-diuretic, suggests an inability of the analogues to bind to capaR and initiate a calcium signalling response. This was supported via screening of the CAP2b analogues in Drosophila $\mathrm{S} 2$ cells which were tested for agonistic properties, affirming an inability of analogues 1896, 1902, 2089 and 2129 to initiate a calcium response. Only analogue 1895 stimulated capaR to produce a calcium response although this was significantly lower in magnitude for both primary and secondary peaks compared to the capa-induced capaR response, Fig. 5a (Terhzaz et al. 2012).

Drosophila melanogaster encodes three putative pyrokinin receptors: CG9918, PK1-R; CG8795, PK2-R2; CG8784, PK2-R1 (Flybase, Grimmelikhuijzen, C.J.P. (2013.6.6). Nomenclature of Pyrokinin receptor-encoding genes). The previous work has shown that $D$. melanogaster PK1 (capa-3 TGPSASSGLWFGPRLamide) and PK2 (renamed PK-gamma, SVPFKPRLamide) and hugin activate calcium signalling via CG8795, PK2-R2 (Choi et al. 2003; Terhzaz et al. 2012). Analogue 1895 has previously been shown to interact with the Tribolium PK receptor (Jiang et al. 2015), and analogue 1902 also contains PK-like motifs 
(PRLamide). In addition, 1896 contains the PRIamide motif, which is also seen, for example, in H. abietis PK-1 (DiNER; Yeoh et al. 2017). Therefore, 1895, 1896 and 1902 were assessed against the functional PK receptor encoded by CG8795. 2129 was not assessed against the PK receptor, as the critical $F$ residue in the PK core FXPRLa, which is required for PK receptor interaction, is replaced with an 'A' in 2129. Analogue 2129 also possesses steric hindrance adjacent to the alpha carbon in the C-terminal position (e.g. as found with Ile or Val) which is strongly preferred for binding to capaR but which will interfere with $\mathrm{PK}$ receptor binding.

More recently, peptides of the capa family have been linked to desiccation and cold tolerance in Drosophila, with the capability (capa) neuropeptide gene found to be desiccation and cold stress responsive (Terhzaz et al. 2015). In addition, knock-down of the capa gene has been shown to increase Drosophila desiccation tolerance (Terhzaz et al. 2015). In the current study, it was the CAP2b/PK analogues that showed the most promise in significantly impacting survival under conditions of desiccation stress, whilst causing minimal effects under conditions of starvation stress. Here, analogues 1895, 1896, 1902 and 2129 significantly impacted female D. suzukii desiccation survival and 1895 , 1902 and 2129 male D. suzukii desiccation survival, whilst having no $(1895,1902)$ or limited $(1896,2129)$ effect on D. melanogaster. These selected neuropeptides offered a protective effect and thus increased survival under desiccation stress. Furthermore, when under conditions of cold stress, all analogues produced a protective effect in $D$. melanogaster males, although failed to impact the survival of female $D$. melanogaster and both male and female $D$. suzukii. The reason for this male $D$. melanogaster-specific effect is unknown. According to the absolute energy demand (AED) hypothesis, larger bodied individuals are hypothesised to be at a disadvantage when under stressful conditions such as thermal stress due to expending energy at a proportionately faster rate than smaller bodied individuals (Reim et al. 2006). Under this hypothesis, smaller bodied $D$. melanogaster males would be considered at an advantage when under cold stress. However, why analogue treatment would significantly affect only $D$. melanogaster male cold stress survival is unknown.

As desiccation survival is tightly linked with fluid secretion by Malpighian tubules, the lack of effect on fluid secretion by many of the analogues tested may explain the desiccation survival phenotypes upon treatment with analogues 1896, 1902 and 2129. The protective effect of these $\mathrm{CAP} 2 \mathrm{~b}$ analogues may also be due to an antagonist response against binding of endogenous capa neuropeptides to capaR in vivo, as both 1896 and 1902 demonstrated an antagonist effect on the heterologous T. castaneum TcCAPAr (Jiang et al. 2015), although further testing is required to confirm this. The inability of both 1896 and 1902 to initiate a $\mathrm{Ca}^{2+}$ response in the $\mathrm{S} 2$ cell assay when targeting the capaR adds support to this. 1896 and 1902 instead showed activation of the pyrokinin receptor, which has not been shown to influence fluid secretion rates (Kean et al. 2002). These findings may indicate a, heretofore unknown, role for PK, and the PK receptor, in desiccation survival.

The current study investigated the effect of biostable kinin and CAP2b/PK analogue treatment on Drosophila stress tolerance (desiccation, starvation and cold temperature stress), focusing on D. suzukii as the target (pest) species and D. melanogaster as a non-target species. Of the kinin and CAP2b/PK analogues, it was the CAP2b/PK analogues which displayed the most promise in altering the relative fitness of treated $D$. suzukii when under conditions of desiccation stress. Of particular interest were analogues 1895 (2Abf-Suc-FGPRLa), 1896 (2Abf-Suc-FTPRIa), 1902 (2Abf-Suc-FKPRLa) and 2129 (2Abf-Suc-ATPRIa), with 1895 and 1902 showing increased promise due to an ability to target the pest $D$. suzukii, whilst leaving the non-pest $D$. melanogaster unaffected.

In order to develop neuropeptide analogues that can reduce survival in pest fruit flies, future directions in analogue design should focus on the inclusion of $D$. suzukii peptide sequences (DiNER; Yeoh et al. 2017), as well as the addition of polyethylene glycol (PEG) polymer moieties that can increase bioavailability characteristics (Boccù et al. 1982; Jeffers and Roe 2008). Testing of new-generation analogues is currently underway with a focus on mode of application to elucidate the most efficacious method of delivery to apply neuropeptide-based insecticides in the field.

\section{Author contributions}

LA, RM, JATD and SAD conceived and designed the research. RJN designed and produced peptide analogues. LA and RM conducted experiments with assistance from AD. LA and RM analysed data. LA wrote the manuscript, and RM, RJN, SAD and AD edited it. All authors read and approved the manuscript.

Funding This work was funded by the European Union's Horizon 2020 Research and Innovation programme under grant agreement No.634361 (SD/JATD) (nEUROSTRESSPEP) and the US Department of Agriculture/Department of Defence Deployed War Fighter Protection Initiative 6202-22000-029-00D (RJN).

\section{Compliance with ethical standards}

Conflict of interest The authors declare that they have no conflict of interest. 
Ethical approval The article does not contain any studies with human participants or animals (vertebrates).

Open Access This article is distributed under the terms of the Creative Commons Attribution 4.0 International License (http://creativeco mmons.org/licenses/by/4.0/), which permits unrestricted use, distribution, and reproduction in any medium, provided you give appropriate credit to the original author(s) and the source, provide a link to the Creative Commons license, and indicate if changes were made.

\section{References}

Alford L, Marley R, Dornan A, Pierre J-S, Dow JAT, Nachman RJ, Davies SA (2019) Assessment of neuropeptide binding sites and the impact of biostable kinin and CAP2b analogue treatment on aphid (Myzus persicae and Macrosiphum rosae) stress tolerance. Pest Manag Sci. https://doi.org/10.1002/ps.5372

Altstein M, Nässel DR (2010) Neuropeptide signaling in insects. Adv Exp Med Biol 692:155-165

Altstein M, Hariton A, Nachman RJ (2013) FXPRLamide (Pyrokinin/ PBAN) family. In: Kastin AJ (ed) Handbook of biologically active peptides. Elsevier, Amsterdam, pp 255-266

Asplen MK, Anfora G, Biondi A, Choi D-S, Chu D, Daane KM, Gibert P, Gutierrez AP, Hoelmer KA, Hutchison WD, Isaacs R, Jiang Z-L, Kárpáti Z, Kimura MT, Pascual M, Philips CR, Plantamp C, Ponti L, Vétek G, Vogt H, Walton VM, Yu Y, Zappalà L, Desneux N (2015) Invasion biology of spotted wing Drosophila Drosophila suzukii: a global perspective and future priorities. J Pest Sci 88:469-494

Atallah J, Teixeira L, Salazar R, Zaragoza G, Kopp A (2014) The making of a pest: the evolution of a fruit-penetrating ovipositor in Drosophila suzukii and related species. Proc R Soc B 281:9

Audsley N, Down RE (2015) G protein coupled receptors as targets for next generation pesticides. Insect Biochem Mol Biol 67:27-37

Becher PG, Jensen RE, Natsopoulou ME, Verschut V, De Fine Licht H (2017) Infection of Drosophila suzukii with the obligate insectpathogenic fungus Entomophthora muscae. J Pest Sci 91:781-787

Boccù E, Velo G, Veronese F (1982) Pharmacokinetic properties of polyethylene glycol derivatized superoxide dismutase. Pharm Res Commun 14:113-120

Cabrero P, Terhzaz S, Romero MF, Davies SA, Blumenthal EM, Dow JAT (2014) Chloride channels in stellate cells are essential for uniquely high secretion rates in neuropeptide-stimulated Drosophila diuresis. Proc Natl Acad Sci USA 111:14301-14306

Cannell E, Dornan AJ, Halberg KA, Terhzaz S, Dow JA, Davies SA (2016) The corticotropin releasing factor-like diuretic hormone 44 (DH44) and kinin neuropeptides modulate desiccation and starvation tolerance in Drosophila melanogaster. Peptides 80:96-107

Choi M-Y, Fuerst E-J, Rafaeli A, Jurenka R (2003) Identification of a $\mathrm{G}$ protein-coupled receptor for pheromone biosynthesis activating neuropeptide from pheromone glands of the moth Helicoverpa zea. PNAS 100:9721-9726

Coast GM, Holman GM, Nachman RJ (1990) The diuretic activity of a series of cephalomyotropic neuropeptides, the achetakinins, on isolated malpighian tubules of the house cricket, Acheta domesticus. J Insect Physiol 36:481-488

Coast GM, Nachman RJ, Lopez J (2011) The control of Malpighian tubule secretion in a predacious hemipteran insect, the spined soldier bug Podisus maculiventris (Heteroptera, Pentatomidae). Peptides 32:493-499

Cobbold PH, Rink TK (1987) Fluorescence and bioluminescence measurement of cytoplasmic free calcium. Biochem J 248:313-328
Davies SA, Huesmann GR, Maddrell SH, O’Donnell MJ, Skaer NJ, Dow JA, Tublitz NJ (1995) CAP2b, a cardioacceleratory peptide, is present in Drosophila and stimulates tubule fluid secretion via cGMP. Am J Physiol 269(6 Pt 2):R1321-R1326

Davies SA, Stewart EJ, Huesmann GR, Skaer NJ, Maddrell SH, Tublitz NJ, Jab Dow (1997) Neuropeptide stimulation of the nitric oxide signaling pathway in Drosophila melanogaster Malpighian tubules. Am J Physiol 273:R823-R827

Davies SA, Cabrero P, Overend G, Aitchison L, Sebastian S, Terhzaz S, Dow JAT (2014) Cell signalling mechanisms for insect stress tolerance. J Exp Biol 217:119-128

Desneux N, Decourtye A, Delpuech JM (2007) The sublethal effects of pesticides on beneficial arthropods. Annu Rev Entomol 52:81-106

Diepenbrock LM, Hardin JA, Burrack HJ (2017) Season-long programs for control of Drosophila suzukii in southeastern US blackberries. Crop Protection 98:149-156

Dow JAT (2009) Insights into the Malpighian tubule from functional genomics. J Exp Biol 212:435-445

Dow JAT, Maddrell SH, Görtz A, Skaer NJ, Brogan S, Kaiser K (1994) The malpighian tubules of Drosophila melanogaster: a novel phenotype for studies of fluid secretion and its control. J Exp Biol 197:421-428

Fanning PD, VanWoerkom A, Wise JC, Issacs R (2018) Assessment of a commercial spider venom peptide against spotted-wing Drosophila and interaction with adjuvants. J Pest Sci 91:1279-1290

Feng Y, Bruton R, Park A, Zhang A (2018) Identification of attractive blend for spotted wing drosophila, Drosophila suzukii, from apple juice. J Pest Sci 91:1251-1267

Frewin AJ, Renkema J, Fraer H, Hallett RH (2017) Evaluation of attractants for monitoring Drosophila suzukii (Diptera: Drosophilidae). J Econ Entomol 110:1156-1163

Garriga A, Morton A, Garcia-del-Pino F (2018) Is Drosophila suzukii as susceptible to entomopathogenic nematodes as Drosophila melanogaster? J Pest Sci 91:789-798

Giorgini M, Wang X-G, Wang Y, Chen F-S, Hougardy E, Zhang H-M, Chen Z-Q, Chen H-Y, Liu C-X, Cascone P, Formisano G, Carvalho GA, Biondi A, Buffington M, Daane KM, Hoelmer KA, Guerrieri E (2018) Exploration for native parasitoids of Drosophila suzukii in China reveals a diversity of parasitoid species and narrow host range of the dominant parasitoid. J Pest Sci. https ://doi.org/10.1007/s10340-018-01068-3

Girod P, Lierhmann O, Urvois T, Turlings TCJ, Kenis M, Haye T (2018) Host specificity of Asian parasitoids for potential classical biological control of Drosophila suzukii. J Pest Sci 91:1241-1250

Halberg KA, Terhzaz S, Cabrero P, Davies SA, Dow JAT (2015) Tracing the evolutionary origins of insect renal function. Nat Commun 6:6800

Hamby KA, Bellamy DE, Chiu JC, Lee JC, Walton VM, Wiman NG, York RM, Biondi A (2016) Biotic and abiotic factors impacting development, behavior, phenology, and reproductive biology of Drosophila suzukii. J Pest Sci 89:605-619

Harshini S, Nachman RJ, Sreekumar S (2002) Inhibition of digestive enzyme release by neuropeptides in larvae of Opisina arenosella (Lepidoptera: Cryptophasidae). Comp Biochem Physiol B 132:353-358

Harshini S, Manchu V, Sunitha VB, Sreekumar S, Nachman RJ (2003) In vitro release of amylase by culekinins in two insects: Opisinia arenosella (Lepidoptera) and Rhynchophorus ferrugineus (Coleoptera). Trends Life Sci 17:61-64

Holman GM, Cook BJ, Nachman RJ (1986) Primary structure and synthesis of a blocked myotropic neuropeptide isolated from the cockroach, Leucophaea maderae. Comp Biochem Physiol C $85: 219-224$

Holman GM, Cook BJ, Nachman RJ (1987) Isolation, primary structure, and synthesis of Leucokinins VII and VIII: the final members of this new family of cephalomyotropic peptides isolated from 
head extracts of Leucophaea maderae. Comp Biochem Physiol $88 \mathrm{C}: 31-34$

Holman GM, Nachman RJ, Coast GM (1999) Isolation, characterization and biological activity of a diuretic myokinin neuropeptide from the housefly, Musca domestica. Peptides 20:1-10

Huang J, Gut L, Grieshop M (2017) Evaluation of food-based attractants for Drosophila suzukii (Diptera: Drosophilidae). Environ Entomol 46:878-884

Huesmann GR, Cheung CC, Loi PK, Lee TD, Swiderek KM, Tublitz NJ (1995) Amino acid sequence of CAP2b, an insect cardioacceleratory peptide from the tobacco hawkmoth Manduca sexta. FEBS Lett 371:311-314

Jeffers LA, Roe RM (2008) The movement of proteins across the insect and tick digestive system. J Insect Physiol 54:319-332

Jiang H, Wei Z, Nachman RJ, Adams ME, Park Y (2014) Functional phylogenetics reveals contributions of pleiotropic peptide action to ligand-receptor coevolution. Sci Rep 4:6800

Jiang H, Wei Z, Nachman RJ, Kaczmarek K, Zabrocki J, Park Y (2015) Functional characterization of five different PRXamide receptors of the red flour beetle Tribolium castaneum with peptidomimetics and identification of agonists and antagonists. Peptides 68:246-252

Kaczmarek KK, Pietrantonio P, Coast G, Zabrocki J, Nachman R (2010) A non-peptide mimetic insect kinin agonist interacts with an expressed receptor and an in vitro diuretic assay in the mosquito Aedes aegypti. J Pept Sci 16:154

Kean L, Cazenave W, Costes L, Broderick KE, Graham S, Pollock VP, Davies SA, Dow JAT (2002) Two nitridergic peptides are encoded by the gene capability in Drosophila melanogaster. Am J Physiol Regul Integr Comp Physiol 282:R1297-R1307

Landolt PJ, Adams T, Rogg H (2012) Trapping spotted wing drosophila, Drosophila suzukii (Matsumura) (Diptera: Drosophilidae), with combinations of vinegar and wine, and acetic acid and ethanol. J Appl Entomol 136:148-154

Leach H, Moses J, Hanson E, Fanning P, Isaacs R (2018) Rapid harvest schedules and fruit removal as non-chemical approaches for managing spotted wing Drosophila. J Pest Sci 91:219-226

Lee RE, Chen CP, Denlinger DL (1987) A rapid cold-hardening process in insects. Science 238:1415-1417

Nachman RJ (2009) Agonists/antagonists of the insect kinin and pyrokinin/PBAN neuropeptide classes as tools for rational pest control. In: Ishaaya I, Horowitz AR (eds) Biorational control of arthropod pests: application and resistance management. Springer, Netherlands, pp 21-48

Nachman RJ, Isaac RE, Coast GM, Holman GM (1997a) Aib-containing analogues of the insect kinin neuropeptide family demonstrate resistance to an insect angiotensin-converting enzyme and potent diuretic activity. Peptides 18:53-57

Nachman RJ, Isaac RE, Coast GM, Roberts VA, Lange A, Orchard I, Holman GM, Favrel P (1997b) Active conformation and mimetic analog development for the Pyrokinin/PBAN and Myosuppressin insect neuropeptide families. In: Hedin PA, Hollingworth RM, Masler EP, Miyamoto J, Thompson DG (eds) Phytochemicals for pest control. ACS symposium series 658 . ACS, Washington, DC, pp 277-291

Nachman RJ, Strey A, Isaac E, Pryor N, Lopez JD, Deng JG, Coast GM (2002) Enhanced in vivo activity of peptidase-resistant analogs of the insect kinin neuropeptide family. Peptides 23:735-745

Nachman RJ, Coast GM, Douat C, Fehrentz JA, Kaczmarek K, Zabrocki J, Pryor NW, Martinez J (2003) A C-terminal aldehyde insect kinin analog enhances inhibition of weight gain and induces significant mortality in Helicoverpa zea larvae. Peptides 24:1615-1621

Nachman RJ, Mahdian K, Nässel DR, Isaac RE, Pryor N, Smagghe G (2011) Biostable multi-Aib analogs of tachykinin-related peptides demonstrate potent oral aphicidal activity in the pea aphid Acyrthosiphon pisum (Hemiptera: Aphidae). Peptides 32:587-594

Pimentel D, Acquay H, Biltonen M, Rice P, Silva M, Nelson J, Lipner V, Giordano S, Horowitz A, Damore M (1992) Environmental and economic costs of pesticide use. Bioscience 42:750-760

Powell SJ, Bale JS (2005) Low temperature acclimated populations of the grain aphid Sitobion avenae retain ability to rapidly cold harden with enhanced fitness. J Exp Biol 208:2615-2620

Radford JC, Davies SA, Dow JA (2002) Systematic G-proteincoupled receptor analysis in Drosophila melanogaster identifies a leucokinin receptor with novel roles. J Biol Chem 277:38810-38817

Reim C, Teuschl Y, Blanckenhorn WU (2006) Size-dependent effects of larval and adult food availability on reproductive energy allocation in the Yellow Dung Fly. Funct Ecol 20:1012-1021

Rosay P, Davies SA, Yu Y, Sözen MA, Kaiser K, Dow JA (1997) Cell-type specific calcium signalling in a Drosophila epithelium. J Cell Sci 110:1683-1692

Schoofs L, Vandenbroeck J, Deloof A (1993) The myotropic peptides of Locusta migratoria: structures, distribution, functions and receptors. Insect Biochem Mol 202:3667-3676

Seinsche A, Dyker H, Lösel P, Backhaus D, Scherkenbeck J (2000) Effect of helicokinins and ACE inhibitors on water balance, and development of Heliothis virescens larvae. J Insect Physiol 46:1423-1431

Sinclair BJ, Chown SL (2006) Rapid cold-hardening in a Karoo beetle, Afrinus sp. Physiol Entomol 31:98-101

Smagghe G, Mahdian K, Zubrzak P, Nachman RJ (2010) Antifeedant activity and high mortality in the pea aphid Acyrthosiphon pisum (Hemiptera: Aphidae) induced by biostable insect kinin analogs. Peptides 31:498-505

Taneja-Bageshwar S, Strey A, Zubrzak P, Pietrantonio PV, Nachman RJ (2006) Comparative structure-activity analysis of insect kinin core analogs on recombinant kinin receptors from Southern cattle tick Boophilus microplus (Acari: Ixodidae) and mosquito Aedes aegypti (Diptera: Culicidae). Arch Insect Biochem Physiol 62:128-140

Taneja-Bageshwar S, Strey A, Isaac RE, Coast GM, Zubrzak P, Pietrantonio PV, Nachman RJ (2009) Biostable agonists that match or exceed activity of native insect kinins on recombinant arthropod GPCRs. Gen Comp Endocr 162:122-128

Terblanche JS, Clusella-Trullas S, Deere JA, Chown SL (2008) Thermal tolerance in a south-east African population of the tsetse fly Glossina pallidipes (Diptera, Glossinidae): Implications for forecasting climate change impacts. J Insect Physiol 54:114-127

Terhzaz S, O'Connell FC, Pollock VP, Kean L, Davies SA, Veenstra JA, Dow JAT (1999) Isolation and characterization of a leucokinin-like peptide of Drosophila melanogaster. J Exp Biol 202:3667-3676

Terhzaz S, Cabrero P, Robben JH, Radford JC, Hudson BD, Milligan G, Dow JA, Davies SA (2012) Mechanism and function of Drosophila capa GPCR: a desiccation stress-responsive receptor with functional homology to human neuromedinU receptor. PLoS ONE 7:e29897

Terhzaz S, Teets NM, Cabrero P, Henderson L, Ritchie MG, Nachman RJ, Dow JAT, Denlinger DL, Davies SA (2015) Insect capa neuropeptides impact desiccation and cold tolerance. Proc Natl Acad Sci USA 112:2882-2887

Terhzaz S, Alford L, Yeoh JGC, Marley R, Dornan AT, Dow JAT, Davies SA (2017) Renal neuroendocrine control of desiccation and cold tolerance by Drosophila suzukii. Pest Manag Sci 74:800-810

Van Hiel MB, Van Loy T, Poels J, Vandersmissen HP, Verlinden H, Badisco L, Vanden Broeck J (2010) Neuropeptide receptors as 
possible targets for development of insect pest control agents. Adv Exp Med Biol 692:211-226

Woltz JM, Donahue KM, Bruck DJ, Lee JC (2015) Efficacy of commercially available predators, nematodes and fungal entomopathogens for augmentative control of Drosophila suzukii. J Appl Entomol 139:759-770

Yeoh JGC, Pandit AA, Zandawala M, Nässel DR, Davies SA, Dow JAT (2017) DINeR: database for insect neuropeptide research. Insect Biochem Mol Biol 86:9-19

Zandawala M, Marley R, Davies SA, Nässel DR (2018) Characterization of a set of abdominal neuroendocrine cells that regulate stress physiology using colocalized diuretic peptides in Drosophila. Cell Mol Life Sci 75:1099-1115

Zhang Q, Nachman RJ, Kaczmarek K, Zabrocki J, Denlinger DL (2011) Disruption of insect diapause using agonists and an antagonist of diapause hormone. Proc Natl Acad Sci USA 108:16922-16926

Publisher's Note Springer Nature remains neutral with regard to jurisdictional claims in published maps and institutional affiliations. 